\title{
Una lectura del mito de Narciso en Luis Cernuda: Luis de Baviera escucha Lohengrin
}

\section{Reading about the Myth of Narcissus in Luis Cernuda's Luis de Baviera escucha Lohengrin}

Concepción López Rodríguez

Universidad de Granada, Granada / España

clopez@ugr.es

Resumen: Luis Cernuda destacó siempre la capacidad expresiva implícita en los mitos griegos y a ellos recurrió en su obra poética. El más importante sin duda es el mito de Narciso, que constituye no un mero ejemplo sino la base estructural de su poesía. En este trabajo presento un análisis de la presencia del mito de Narciso en el poema "Luis de Baviera escucha Lohengrin", perteneciente a la última sección de $L a$ realidad y el deseo, la titulada Desolación de la Quimera. Tras exponer algunos ejemplos en obras precedentes, llego a la conclusión de que en este poema, Luis de Baviera, Luis Cernuda y Narciso son el mismo personaje, y que la música discurre como sonora corriente de agua donde se reflejan la imagen del rey y del poeta, espejo donde ambos hallan la culminación del deseo de sí mismos.

Palabras clave: Narciso; Luis Cernuda; Luis de Baviera; poesía; música.

Abstract: Luis Cernuda always stressed the expressive potential implicit in Greek myths, and made a constant use of them in his poetic work. Without a doubt the most important of these myths to his work is the myth of Narcissus, which becomes not only a mere example but also the structural base of his poetry. In this article I present an analysis about the presence of the myth of Narcissus in the poem "Luis de Baviera escucha 
Lohengrin" (Ludwig of Bavaria listens to Lohengrin), which belongs to the last section of Cernuda's work La Realidad y el Deseo, called Desolación de la Quimera. After showing some examples from some of his previous work, I get to the conclusion that in this poem, Ludwig of Bavaria, Luis Cernuda and Narcissus are the same character. I also verify that the poem's music flows as a sounding current where the images of both the king and the poet are reflected, a mirror where they both find the culmination of their own desire.

Keywords: Narcissus; Luis Cernuda; Ludwig of Bavaria; poetry; music.

Recebido em: 20 de março de 2017.

Aprovado em: 2 de julho de 2017.

Quede constancia en primer lugar del papel decisivo que los mitos griegos desempeñaron en la obra poética de Luis Cernuda, incluso como impulsores de su vocación. De ello nos da reiterado testimonio el propio poeta:

[...] Que tú no comprendieras entonces la causalidad profunda que une ciertos mitos con ciertas formas intemporales de vida poco importa: cualquier aspiración que haya en ti hacia la poesía aquellos mitos helénicos fueron quienes la provocaron y la orientaron. (CERNUDA, 1977, ${ }^{1}$ p. 31 ).

El poeta asimismo nos refiere esa capacidad expresiva, ya objeto de nostalgia por su desaparición, contenida en los mitos clásicos. El poema en prosa "Marsias" testimonia este hecho, al margen de incluir

\footnotetext{
${ }^{1}$ Está también en Ocnos. De esa obra se publicaron tres ediciones. La primera data de 1942 (Londres, Dolphin). La segunda edición, aumentada, data de 1949, que en realidad presentó una doble alternativa: una edición normal de 46 poemas y otra especial donde se incluyen los poemas titulados "El poeta y los mitos" y "El enamorado", que habían sido eliminados de la edición normal por la censura. La presente cita y todas las restantes tomadas de la obra en prosa de Luis Cernuda pertenecen a la edición de la Prosa completa, llevada a cabo por Derek Harris y Luis Maristany (1975).
} 
densa, pero llena de pathos, una manifestación de su credo poético y tocar tangencialmente la temática del narcisismo:

Un sentimiento desconocido antes, deleite físico y espiritual a un tiempo, le invadió al escuchar así su propia voz [se refiere a Marsias, que representa también la voz poética de Luis Cernuda], trasformada y enajenada, pero en la que se reconocía inconfundiblemente a sí mismo. Quien aquella zampoña arrojara al agua (continúa la leyenda), era la diosa Minerva, despechada porque en el agua vio reflejado el esfuerzo que, para despertar la melodía, deformaba su divino semblante. [...]

Los mitos paganos eran trágicamente hermosos y en su elocuencia trágica había una trágica hermosura. Cuando los hombres de hoy quieren expresar de otro modo lo que en alguno de aquellos mitos se cifra, necesitan hablar mucho, lo cual es vulgar y está mal y tras hablar mucho en conclusión nada expresan, lo cual es más vulgar y está aún peor.

Así, pues, y en las menos palabras, ¿qué se cifra simbólicamente en ese mito de Marsias? Que el poeta debe saber cómo tiene frente de sí a toda la creación, tanto en su aspecto divino como en el humano, enemistad bien desigual en la que el poeta, si lo es verdaderamente, ha de quedar vencido o muerto. (CERNUDA, 1975, p. 1092) ${ }^{2}$.

Cumplió fielmente el poeta Luis Cernuda la lección implícita en sus propias palabras, y no solo se sirvió del mito como ejemplo en su obra, sino que su vida la elevó a la categoría de mito. Es, pues, en esta secuencia donde hay que inscribir las siguientes palabras.

\footnotetext{
${ }^{2}$ Este texto, "Marsias", fue publicado en 1941 y fue incluido en Poesía y literatura II, libro que se editó tras la muerte de Luis Cernuda y cuya impresión data de 1965 ("Biblioteca Breve", de Seix Barral, Barcelona).
} 
Ahora bien, de todos los mitos griegos ${ }^{3} \mathrm{y}$ de todos aquellos que cita o usa el poeta sevillano hay uno que emerge de su obra por su singular importancia: es el mito de Narciso, cuya historia incluso es sugerida en el decurso de otros mitos o leyendas. De su historia poética en Cernuda daré cuenta, centrándome, bien es verdad, en el poema "Luis de Baviera escucha Lohengrin", poema incluido en la última sección de su obra poética, en Desolación de la Quimera. No irrumpe de manera inesperada en sus versos tardíos integrantes de esta última sección de La realidad y el deseo ${ }^{4}$ el bello Narciso. Para justificar su presencia aquí, o mejor dicho, para comprenderla mejor, se ha de hacer un viaje hacia atrás, en el tiempo de la obra poética del sevillano, y un retroceso también en su vida. Cuando Luis Cernuda, allá por el año 1936, decide publicar su obra poética bajo un título, su propósito estaba ideado con una proyección futura a largo plazo, un plazo tan largo como su vida, y tenía una clara intencionalidad: crear o recrear un mito. La realidad y el deseo, título de su obra poética, no es, por tanto, un título conferido por el autor a todos sus libros de poesía agrupados en una mera secuencia cronológica abierta, sino la descripción poética de una existencia que se eleva a nivel de símbolo, de mito, en cuya historia intervienen el poeta Luis Cernuda y su realidad, la poesía donde se proyecta (se refleja) para alcanzar su deseo (configurar su leyenda, su inmortalidad). Estos son los tres pilares (hombre, arte y deseo) que constituyen el sustrato de su obra poética y en realidad de su vida.

\footnotetext{
${ }^{3}$ Para comprender la función de Grecia en la obra de Luis Cernuda, puede consultarse mi trabajo El mito de Grecia en Luis Cernuda (1979).

${ }^{4} \mathrm{La}$ realidad y el deseo conoció varias ediciones en vida de Luis Cernuda. La primera data de 1936 e incluye hasta el libro Invocaciones a las gracias del mundo (en Madrid, Ediciones del Árbol). La segunda edición data de 1940 (en México, Editorial Séneca) e incluye como nueva sección Las nubes. La tercera edición data de 1958 y fue publicada en México, Fondo de Cultura Económica; incluye tres secciones nuevas y parte de una inconclusa: Como quien espera el alba, Vivir sin estar viviendo, Con las horas contadas y una sección XI (sin título, inacabada) que más tarde conformaría la última sección del libro con el título Desolación de la Quimera y que fue publicada ya con este título de manera independiente en 1962. La cuarta edición de La realidad y el deseo fue publicada, con posterioridad a la muerte de Luis Cernuda, en México, Fondo de Cultura Económica en 1964, y contiene todas las secciones.
} 
En un breve, pero necesario, recorrido por la trayectoria del mito, me sitúo al comienzo de su carrera poética. Su primer libro, ${ }^{5}$ Perfil del aire, se publicó en una colección de suplementos de la revista Litoral; sería un libro de corta vida. Cernuda lo sometió a profundas transformaciones, encaminadas, fundamentalmente, a engarzarlo, bajo el título de Primeras poesías, en el conjunto orgánico que ya era La realidad y el deseo. Uno de los poemas del libro primigenio (Perfil del aire) es el que comienza con el verso "La fuente que se ha roto", que a continuación cito:

La fuente que se ha roto

Una vida se sustenta.

Enajenar las lágrimas

El instante quisiera.

Cruza la soledad

Una paloma rubia

Y su nido levanta

En la caja de música.

Enjugando su voz

La sirena no vuelve.

¿Cuándo abrirá la imagen

Orillas de la fuente?

Si se ha perdido el mármol

Que un espejo cercaba

Aún le queda al sentido

Este vidrio del agua

El labio está sin sed

Porque el cuerpo se olvida.

En el agua del vaso

Se anega la desdicha.

\footnotetext{
${ }^{5} \mathrm{Al}$ Narciso de estos primeros libros (Perfil del aire, Primeras poesías y Égloga, elegía y oda) le dediqué ya algunas páginas en mi trabajo ya citado en nota 3. Decía literalmente por aquellos años de 1978: "El segundo poema en que la música está presente es 'Luis de Baviera escucha a Lohengrin'. En este se halla desarrollado el mito de Narciso" (LÓPEZ RODRÍGUEZ, 1978, p. 80). Posteriormente lo traté en "Luis Cernuda: la construcción de un mito" (1998, p. 75-85). De este último trabajo se hallan aquí algunas referencias.
} 
En este poema, excluido del libro final (Primeras poesías), se aprecia ya la irrupción más o menos alusiva o velada del joven Narciso en una identificación con el adolescente (Luis Cernuda): la fuente rota es el espejo donde la imagen del adolescente había parecido cobrar forma (autoerotismo), pero desemboca en la destrucción del mito ("El labio está sin sed porque el cuerpo se olvida") a pesar del consuelo que le procura "el agua del vaso". ¿Qué razones le llevaron a Cernuda a suprimir este poema del libro primigenio Perfil del aire y, en consecuencia no introducirlo en el definitivo Primeras poesías? Las razones pueden ser múltiples: ¿acaso porque le sonaba demasiado pretencioso o quería anular cualquier resonancia de la equivocada crítica que lo tachó de imitar a Jorge Guillén, trastocando con ello la misma fecha de composición de Perfil del aire ? ${ }^{6}$ Pero Cernuda conservó otro poema de temática narcisista con algún cambio relevante. Es el poema que cito a continuación en su doble versión. Así aparece en Perfil del aire:

Le goza en sueño azogado

Tras espacio infranqueable

Al narciso enamorado.

Entre ramaje dorado

Agua helada se desata

Y humanas rosas dilata

En su inmóvil paroxismo

Quedando solo en su abismo

Fugaz memoria de plata.

Y así aparece en Primeras poesías:

XIII

Se goza en sueño encantado,

Tras espacio infranqueable,

Su belleza irreparable

El Narciso enamorado.

\footnotetext{
${ }^{6}$ No hay que olvidar el rencor constante que alimentó en Cernuda la poca favorable acogida que tuvo Perfil del aire, que fue tachado de poco original y de estar influenciado por Guillén, aunque verdaderamente Cántico data de 1928 y Perfil del aire data de 1927. Cf. "El crítico, el amigo, el poeta: diálogo ejemplar" (CERNUDA, 1975, p. 878-897).
} 


\author{
Ya diamante azogado \\ O agua helada, allá desata \\ Humanas rosas, dilata \\ Tanto inmóvil paroxismo. \\ Mas queda sólo en su abismo \\ Fugaz memoria de plata.
}

Las razones del cambio en diferentes versos me provoca la siguiente sugerencia: desde el punto de vista del recorrido del mito, cuya configuración nos parece posterior a la composición del libro aislado Perfil del aire, tal vez tenga más lógica poética el poema de la misma temática incluido en Primeras poesías (1924-1927). Recuérdese el acontecimiento que el propio Cernuda nos relata en Historial de un libro y que constituye un principio de cohesión poética en lo referente al mito de Narciso ("Por idénticas fechas, sobre todo, comencé a leer a André Gide [...] Me figuro que Salinas no podía suponer que con esa lectura me abría el camino para resolver, o para reconciliarme, con un problema vital mío decisivo [...] La sorpresa, el deslumbramiento que suscitaron en mí muchos de los Morceaux, no podría olvidarlos nunca; allí conocí a Lafkadio, y quedé enamorado de su juventud, de su gracia, de su libertad, de su osadía"7). Y digo cohesión poética porque, según algunos críticos, el mito de Narciso le fue sugerido a Cernuda por André Gide; pero he de añadir otra circunstancia indicada por el propio Cernuda: la importancia de los mitos griegos en su iniciación poética y su estima por ellos. Ambos caminos son concomitantes y no se excluyen

\footnotetext{
${ }^{7}$ El propio Luis Cernuda dedicó a A. Gide numerosas páginas. De ellas, cito el siguiente texto extraído de "André Gide" (incluido en Poesía y literatura), cuya fecha de composición data de 1946 y cuya publicación primera es de 1951 en la revista Asomante; lleva a pie de página la nota: "Como homenaje a André Gide": "No cabe duda, el mozo Gide se interesa y se complace en sí mismo, con un narcisismo del que hoy, por una parte, sería trivial y superficial hacerle reproche; y por otra, además de ser esa actitud natural y disculpable en la juventud, que la complacencia en la propia personalidad ha proporcionado a la literatura francesa rica fuente de observación humana [...] Gide, en todo caso, no queda descontento tras la propia contemplación y examen preliminar de sí, y en el año que imprime anónimamente Les Cahiers d'André Walter da también al público Le Traité du Narcisse" (CERNUDA, 1946, p. 810).
} 
necesariamente. Da testimonio el propio Luis, en su "Como homenaje a Gide", de la importancia y calma que le proporciona al autor francés el descubrimiento en sí mismo de la leyenda griega que hiciera inmortal a Narciso y que justificara en el fondo su propia actitud. En la versión de Primeras poesías el joven Narciso aparece nombrado explícitamente ("El Narciso enamorado"), con nombre propio, el personaje mítico, mientras que en la versión de Perfil del aire el verso referido es enunciado como "al narciso enamorado", dejando tal vez la libre elección de interpretar la palabra en un doble sentido. Todo ello viene a demostrar que Luis Cernuda al cambiar el texto tenía una intencionalidad clara y que esa intencionalidad es consustancial a la configuración de La realidad y el deseo como la historia de un mito. En la siguiente sección de La realidad y el deseo (Égloga, Elegía y Oda) también aparece la figura de Narciso en una estructura formal de corte clásico. Como muy dice Manuel Ulacia, ${ }^{8}$ "Cernuda define por primera vez su deseo en la imagen idealizada del actor George O'Brian”. Sin embargo, el personaje real aparece revestido con la aureola de un joven dios. Concretamente es la "Oda" quien nos presenta a este joven dios cinematográfico (equivalente no cabe duda de Narciso), revestido y dotado también de una simbología de eco mallarmeniano. ${ }^{9}$ Cernuda escribe este canto (pues es un poema con un gran sentido musical) donde vemos la figura perfecta, intachable, del dios Narciso (como George O`brian) surgiendo desde la luz:
$[\ldots]$
Desde la luz, el más puro camino
Con el furor que pisa compitiendo,
Vivo, bello y divino
Un joven dios avanza sonriendo
$[\ldots]$
A su vigor tan pleno
La libertad conviene solamente,
No el cuidado vehemente

\footnotetext{
${ }^{8}$ Cf. ULACIA, 1990, p. 40.

${ }^{9}$ Es útil a este respecto el trabajo de G. Correa, "Mallarmé y Garcilaso en Cernuda" (In: HARRIS, 1977, p. 228).
} 
De las terribles y fugaces glorias

Que el amor más ardiente

Halla en fin tras sus débiles victorias.

Así en su labio enamorada nace

Sonrisa luminosa, dilatando

Por el viril semblante la alegría.

Y la antigua tristeza ya deshace,

Desde el candor primero gravitando,

La amargura secreta que nutría.

El cuerpo ya desvía

La natural crudeza

En hermosa destreza

Que por los tensos músculos remueve.

Y a la orilla cercana, al agua leve,

La forma tras su extraña imagen salta,

Relámpago de nieve

Bajo la luz difusa de tan alta

Como se aprecia tras la lectura atenta de estos sonoros versos, la leyenda expuesta en ellos básicamente coincide con el mito de Narciso: como en la leyenda griega, también aquí el joven dios se enamora de su imagen y se fusiona con ella. Ambas contienen un rasgo homosexual, pues sabemos que Narciso, después de despreciar a muchas, fue castigado por Némesis, ${ }^{10}$ haciendo que se enamorara de sí mismo al verse en el espejo de las aguas, acabando por consumirse y convertirse en la flor del narciso. La propuesta de Cernuda siempre se detiene, si llega, en la fusión del personaje real con su imagen; no le interesa en absoluto la posterior transformación, porque en realidad lo que el poeta sevillano quiere destacar es este componente homosexual y la fuerza del deseo, así como el papel intermediario y decisivo de las aguas, que pueden ser reemplazadas por otro elemento como la poesía o la música. También la "Égloga" y la "Elegía" desarrollan diversos aspectos del mito en clave casi coral:

${ }^{10}$ Aunque, evidentemente, hay muchas fuentes bibliográficas para citar la historia de Narciso, aquí he recogido la versión que ofrece A. Ruiz de Elvira (1975). 


\section{Elegía}

$[\ldots]$

¿Vive o es una sombra, mármol frío

En reposo inmortal, pura presencia

Ofreciendo su estéril indolencia

Con un claro, cruel escalofrío?

Al indeciso soplo lento oscila

El bulto langoroso; se estremece

Y del seno la onda oculta crece

Al labio donde nace y se aniquila.

Equívoca delicia. Esa hermosura

No rinde su abandono a ningún dueño;

Camina desdeñosa por su sueño,

Pisando una falaz ribera oscura.

En suma, existe una recurrencia del mito de Narciso en la obra cernudiana, bien sea a nivel de alusión breve, bien en un desarrollo completo. Ya lo dice el propio poeta en "Memoria del cielo":

Narciso sin moralidad, su belleza siempre orillas de mí, sólo dejaré la memoria de una imagen contemplada en el espejo [...]. Seré un ángel, vocación impuesta, no electiva, pero los demás nunca verán mis alas y sólo sabré alisarlas en el agua que engaña mi nostalgia de cielo. (CERNUDA, 1975, p. 1143-44)

Ahora bien, en cada etapa Cernuda le dio a este tema y a otros muchos un tratamiento diferente de acuerdo con una percepción distinta de la poesía. Por ello no es de extrañar que este último Narciso sea más complejo, tal vez menos aparente, pero sin duda soberbio.

En este sentido se puede decir que la poesía de Luis Cernuda es una autobiografía espiritual; él mismo nos lo dice y lo pone de manifiesto al exponernos en prosa la experiencia que subyace a la poesía; así, Historial de un libro ${ }^{11}$ nos sirve de guía para seguir paso a paso aquél recorrido

${ }^{11}$ El propio Cernuda dice al comienzo de Historial de un libro (1958): "Debo excusarme, al comenzar la historia del acontecer que se halla tras los versos de La realidad y el 
vital que subyace al universo poético: el libro al que alude el autor es su propia poesía contemplada desde sí mismo. Este libro también nos sirve de referente para constatar lo que en este contexto se exponga. Pero aquí nos hallamos al final de un proceso y al final de una obra poética. Todo ello se aprecia en el tono de esta última sección de La realidad y el deseo, que es Desolación de la Quimera, título que naturalmente trae resonancias clásicas, aunque estén mediatizadas por otros poetas. En realidad, eso poco importa aquí. Y dentro de esta undécima sección figura el poema titulado "Luis de Baviera escucha a Lohengrin", de gran relevancia y calidad. Imaginemos una superposición de personajes y de situaciones: Luis de Baviera asiste a la representación de Lohengrin, y ante él, en el escenario, transcurre una leyenda, un argumento, que en realidad está relegado en la mente del rey porque a través de la música o por la música se produce una evasión de la realidad escénica concreta, y únicamente esa música hace soñar al rey, en esa música vive; en sus sueños se reproduce otra historia, la de su desdoblamiento, de tal forma que Luis de Baviera se identifica con la imagen que de sí mismo le transmite la música a modo de espejo y en esa imagen melodiosa se reconoce y se funde. Al margen de ello, hay naturalmente otra lectura del tema: Luis de Baviera se identifica con Luis Cernuda, la música de Wagner se identifica con la poesía de Cernuda, y la fusión producida entre el personaje real (sea Luis de Baviera sea Luis Cernuda) con la imagen que le proyecta su arte es la culminación de sus sueños, es la instauración en el mito. Ellos, Luis de Baviera y Luis Cernuda, se equiparan a su vez a Narciso, quien al ver su imagen reflejada en las aguas salta en pos de su imagen. Por tanto, ante la pregunta: ¿Qué misterio nos desvela este título? Es el misterio del deseo, puedo decir. La frustración de la realidad en el autor se trasluce en ansia de crear otra realidad más poderosa donde se fusionan esa otra nueva realidad y sus aspiraciones. Para llevar a cabo este proceso real y poético, Cernuda acude de manera sutil, hermosa y finalmente trágica al gran caudal de inspiración que son los mitos griegos: paso a paso hemos visto surgir la figura del

deseo, por tener que referir, juntamente con las experiencias del poeta que creó aquéllos, algunos hechos en la vida del hombre que sufriera éstas. No siempre será aparente la conexión entre unos y otras, y al lector corresponde establecerla, si cree que vale la pena y quiere tomarse la molestia". Cf. "Historial de un libro" (CERNUDA, 1975, p. 898). 
adolescente Narciso, lo vemos avanzar después como joven dios y lo vemos transformarse en poderoso rey que en la música se refleja a modo de corrientes aguas traslúcidas. Pero cada una de estas fases del mito tiene un cariz diferente y el poeta se instala siempre en un nuevo escenario que contiene esencia de lo griego al unísono con marcado acento innovador e incluso transgresor, y que contiene un acopio de saber transmitido junto a una valiente creación innovadora.

El punto ahora marcado, como he dicho, es casi el final del proceso. Este final está inscrito en el círculo de la obra poética de Cernuda que se cierra con Desolación de la Quimera. La importancia del poema "Luis de Baviera escucha a Lohengrin" en el contexto de este libro ha sido sugerido por el propio autor ${ }^{12}$ y subrayado por la crítica: ${ }^{13}$ "Luis de Baviera escucha Lohengrin" fue uno de los poemas de la última colección que más satisfizo a Cernuda, según se desprende de su Epistolario. En efecto, en él está implícito no solo su credo vital sino también su posición artística, si es que en Cernuda se pueden separar ambos parámetros, que claramente no es posible: arte y vida eran solo una cosa porque para el poeta sevillano la poesía era igual a la vida.

En esta etapa de su producción, el poeta proyecta sus palabras ya sea sobre un personaje histórico ya sobre una situación, de manera que su yo se hace sentir tras los protagonistas aparentes del poema que desarrollan su historia; podemos decir que por lo general el personaje histórico es un paradigma del referido yo artístico. Luis Cernuda acepta e incorpora a su manera de hacer poesía la propuesta, entre otros autores, por Robert Browning: ${ }^{14}$

${ }^{12}$ Cf. CERNUDA, 2003, p. 883 y 885.

${ }^{13}$ J. Teruel (2013, p. 221) lo dice con claridad: "Y precisamente el poema que comentamos, de noviembre de 1960, va a escenificar uno de los motivos centrales de la obra posterior a Donde habite el olvido: la salvación a través de la voluntad artística". ${ }^{14}$ Este texto proviene de los papeles legados por Cernuda a Concha de Albornoz. No consta la fecha. Fue escrito en Gran Bretaña. Se conservan dos copias mecanografiadas en Sevilla (Cf. CERNUDA, 1975, p. 1538). Además, en Historial de un libro Cernuda declara lo que aprendió de la lírica inglesa, en particular de Browning: "[...] proyectar mi experiencia emotiva sobre una situación dramática, histórica o legendaria (como en 'Lázaro', 'Quetzalcóatl', 'Silla del rey', 'El César') [...] Así fue el norte completando en mí, meridional, la gama de emociones sensoriales” (CERNUDA, 1975, p. 923). Recuerdo 
[...] lo típico y constante en la obra de Browning no es expresar su propia experiencia del mundo, sino aquella de otros, animando con pasiones dramáticas seres distintos del propio autor, a quienes éste da voz en soliloquios o monólogos de extensión diversa. El carácter dramático cualifica los versos de Browning, y al decir dramático entiéndase el desarrollo dramático indirecto de un conflicto espiritual, latente en las palabras con que sus personajes nos hablan. En Browning lo dramático no pretende exceder a la palabra, sino que queda más acá de ésta, con el recato y la sinceridad de quien habla en un confesionario. Ya su primera obra poética, Paulina, lleva el subtítulo "Fragmento de una confesión".

Mas como sus versos no presentan los caracteres en acción, sino el desenvolvimiento de una pasión en las almas, de ahí el fracaso del dramaturgo y el triunfo del poeta dramático. (CERNUDA, 1975, p. 1441).

En este magnífico "Luis de Baviera escucha Lohengrin" cumple también una destacada función la música, ${ }^{15}$ tan querida para Luis Cernuda,

que Cernuda no refiere en Historial de un libro ningún testimonio relativo a su último libro de poemas Desolación de la Quimera ni siquiera lo cita por razones cronológicas pero, de hecho, aquel aprendizaje suyo a partir de la lírica inglesa en su conjunto, y en particular de Browning, es más que evidente en el poema que comentamos.

${ }^{15}$ El libro Ocnos, cuyos poemas en prosa se instalan cronológicamente en la infancia del poeta, nos brinda la oportunidad de comprobar la trascendencia que la música tuvo en la vida del poeta Luis Cernuda. El mismo nos lo dice en este importantísimo contexto de su infancia y primera juventud, al margen de su reiterada presencia en la obra poética: "Allí oí por primera vez a Bach y a Mozart; allí reveló la música a mi sentido su pure délice sans chemin (como dice el verso de Mallarmé, a quien yo leía por entonces), aprendiendo lo que para el pesado ser humano es una forma equivalente del vuelo, que su naturaleza le niega. Siendo joven, bastante tímido y demasiado apasionado, lo que le pedía a la música eran alas para escapar de aquellas gentes extrañas que me rodeaban, de las costumbres extrañas que me imponían, y quién sabe si hasta de mí mismo.

Pero a la música hay que aproximarse con mayor pureza, y sólo desear en ella lo que ella puede darnos: embeleso contemplativo. En un rincón de la sala, fijos los ojos en un punto luminoso, quedaba absorto escuchándola, tal quien contempla el mar. Su 
de forma que constituye un doble de la poesía y la poesía a su vez es el correlato de las aguas míticas donde el joven Narciso divisa su figura:

Sólo dos tonos rompen la penumbra:

Destellar de algún oro y estridencia granate.

Al fondo luce la caverna mágica

Donde unas criaturas, ¿de qué naturaleza?, pasan

Melodiosas, manando de sus voces música

Que, como fuente escondida, lenta fluye

$\mathrm{O}$, crespa luego, su caudal agita

Estremeciendo el aire fulvo de la cueva

Y con iris perlado riela en notas.

Ya desde los primeros versos del poema se aprecia ese acoplamiento entre música y agua, y también esa fusión de elementos clásicos con mitología escandinava patente en la figura del elfo. Ello nos evoca el primer poema de esta sección "Mozart", donde Luis Cernuda escribe: "Desde la tierra mítica de Grecia / Llegó hasta el norte el soplo que la anima/ Y en el norte halló eco, entre las voces/ De poetas, filósofos y músicos [...]". Diversamente expresado, pero esencialmente igual, es el pensamiento implícito en ambos textos. Además de los elementos señalados (música, sur-norte etc.) hay que destacar un rasgo vinculado a ellos: la soledad del protagonista y naturalmente, en consecuencia, la soledad ${ }^{16}$ del poeta:

Sombras la sala de auditorio nulo.

En el palco real un elfo solo asiste

Al festejo del cual razón para dar y enigma

armonioso ir y venir, su centelleo multiforme, eran tal ola que desalojase las almas de los hombres. Y tal ola que nos alzara desde la vida a la muerte, era dulce perderse en ella, acunándonos hacia la región última del olvido" (CERNUDA, 1975, p. 63).

16 "La lectura de este [...] testamento poético de Cernuda, de esta desolada poesía de tremenda soledad incurable, nos sobrecoge y estremece, y si esta emoción es la que ha de sentir cualquier lector capaz de sentir la verdadera poesía, cuánta mayor y más dolorosa ha de ser para los que en vida del poeta fuimos o quisimos ser sus amigos e intentamos comprender el misterio de un alma bajo todos conceptos excepcional, a la que no se puede medir ni calificar con instrumental conocido por más aguzado que nos lo procuremos para el caso". Son palabras de Gerardo Diego referentes al libro Desolación de la Quimera. 
$[\ldots]$

Los ojos entornados escuchan, beben la melodía

Como una tierra seca absorbe el don del agua

La superposición de secuencias es muy importante en este poema, y si tuviéramos que desmontarlo comprobaríamos lo intrincado del proceso. Y, aunque alguna quede en el camino, la tarea merece la pena. Pero exige un lento caminar por sus versos. En el escenario poético aparece Luis de Baviera, que es un rey pero también es un elfo, una divinidad escandinava. Este Luis-elfo "asiste a una doble fiesta": la obra musical que escucha y contempla: fiesta exterior. Además hay otra fiesta, otro espectáculo, que es interior; pero tanto la exterior como la interior son la misma fiesta que se fusiona:

Asiste a una doble fiesta: una exterior, aquella

De que es testigo: otra interior allá en su mente,

Donde ambas se funden

[...]

Así, razón y enigma, el poder le permite

A solas escuchar las voces a su orden concertadas,

El brotar melodioso que le acuna y nutre

Los sueños, mientras la escena desarrolla, Ascua litúrgica, una amada leyenda.

La maestría de la estructura lingüística del poema se hace evidente en expresiones tales como "brotar melodioso", cuya lectura evoca ese doble plano magistralmente acoplado del manantial de una fuente, de su sonoro discurrir y a su vez del discurrir armonioso de la música. Ambos ámbitos son el alimento de los sueños del rey (= poeta= Luis Cernuda), que se elevan al compás de la leyenda que transcurre en el escenario. La vida del rey, su auténtica vida, son los sueños:

Adonde vive su reino verdadero, que no es de este mundo:

Donde el sueño le espera, donde la soledad le aguarda.

Donde la soledad y el sueño le ciñen su única corona. 
Pero el rey es mortal, no permanece ajeno al deseo (no se identifica, por tanto, con el joven dios de la "Oda", que altiva e inmutablemente, sin esfuerzo ni agonía se lanza en pos de su sublime imagen desprovista de cualquier deterioro) y sufre la tiranía de un cuerpo joven. Esta servidumbre de la humana hermosura es sentida por el rey y había sido sentida, tal y como se refleja en su obra poética y su obra en prosa, por el poeta sevillano en reiteradas ocasiones, siendo esta además una de las constantes de su vida:

Flotando sobre música el sueño ahora se encarna:

Mancebo todo blanco, rubio, hermoso, que llega

Hacia él y que es él mismo. ¿Magia o espejismo?

¿Es posible a la música dar forma, ser forma de mortal alguno?

¿Cuál de los dos es él, o no es él, acaso, ambos?

El rey no puede, ni aun pudiendo quiere dividirse a sí del otro.

Sobre la música inclinado, como extraño contempla

Con emoción gemela su imagen desdoblada

Y en éxtasis de amor y melodía queda suspenso.

En estos versos se concentra el núcleo fundamental de la temática que desarrolla el presente trabajo. La leyenda que desarrolla el texto se puede descifrar de la manera siguiente: el deseo por un cuerpo joven halla finalmente el fracaso y el rey-poeta se repliega sobre sí mismo, en su estéril soledad, y a través de su arte, poesía o música, según se mire, que actúa prácticamente como metaxú, ${ }^{17}$ se perpetúa en su leyenda: "Y en éxtasis de amor y melodía queda suspenso". Narciso ha saltado en pos de su imagen a través de sus aguas como Luis de Baviera y Luis Cernuda, bien a través de la música bien a través de su poesía, consolidan su leyenda. Pero ¿podemos

\footnotetext{
${ }^{17}$ Este concepto está presente en la obra platónica (PLATON, El banquete, d-e). Diotima contesta a la pregunta de Sócrates con respecto al Amor: "[...] algo intermedio entre mortal e inmortal [...] Interpreta y transmite a los dioses las cosas humanas y a los hombres las cosas divinas, las súplicas y los sacrificios de los unos y las órdenes y las recompensas a los sacrificios de los otros. Colocado entre unos y otros rellena el hueco, de manera que el Todo quede ligado consigo mismo". Traducción de Luis Gil Fernández.
} 
decir que el arte, sea música sea poesía, es un mero "intermediario"?18 Es algo más: es vida. Porque en realidad la música o la poesía en su caso son las que actuaron de desencadenantes no solo las que prestaron sus melodiosos y traslúcidos sones para que se reflejara el sueño: "Mas no, no es eso: es la música quien nutriera a su sueño, le dio forma. / Su sangre se apresura en sus venas, al tiempo apresurando".

Entonces el verdadero intermediario es el rey o el poeta y la fuerza desencadenante del deseo es el arte:

En el vivir del otro el suyo certidumbre encuentra, Sólo el amor depara al rey razón para estar vivo, [...]

Se inclina y se contempla en la corriente

Melodiosa e, imagen ajenada, su remedio espera

Al trastorno profundo que dentro de sí siente. [...]

Los dioses escucharon, y su deseo satisfacen

(Que los dioses castigan concediendo a los hombres

Lo que éstos les piden), y el destino del rey,

Desearse a sí mismo, le transforma, [...]

Las sombras de sus sueños para él eran la verdad de la vida No fue de nadie, ni a nadie pudo llamar suyo.

Si tuviera que resumir poéticamente la vida de Luis Cernuda, no hallaría mejor ni más bella descripción que la expresada en estos dos últimos versos: "Las sombras de los sueños para él (Luis de Baviera = Luis Cernuda) eran la verdad de la vida/ No fue de nadie, ni a nadie pudo llamar suyo". Si Píndaro, en su momento, enunció con breves palabras el destino del ser vivo, del hombre, al decir, en la Pítica VIII, "el hombre es el sueño de una sombra", ${ }^{19}$ palabras que han sido una y

${ }^{18}$ Digamos que en este sentido Cernuda va mucho más allá que el propio Adam Zagajewski, en cuya obra el concepto de metaxú ha sido recientemente estudiado. Cf. A. E. Díaz-Pintado Hilario, Las ideas estéticas de Adam Zagajewski y sus fuentes clásicas (2012). Concretamente las siguientes palabras (p.707) nos pueden ilustrar sobre esta diferencia: "Una vez más, el arte como eficaz metaxý, que pone en comunicación la vida cotidiana con los momentos de deslumbramento". En este contexto, la palabra intermediario le concede al arte un papel destacado pero no tan determinante ni tan excluyente como vemos en Cernuda.

${ }^{19}$ PINDARO, Pítica VIII, 134-135. Traducción de Alfonso Ortega. 
otra vez recordadas, aquí Cernuda reinvierte la expresión y el sujeto deviene lo aparentemente menos real y más vago; cobra entidad el poder de los sueños, incluso reducidos al mero matiz de "sombras". Ello lleva implícito una gran dosis de soledad y ensimismamiento:

Ahora el rey está ahí, en su palco, y solitario escucha, Joven y hermoso, como dios nimbado

Por esa gracia pura e intocable del mancebo,

Existiendo en el sueño imposible de una vida

Que queda sólo en música y que es como música,

Fundido como el mito al contemplarlo, forma ya de ese mito

De pureza rebelde que tierra apenas toca,

Del éter huésped desterrado. La melodía le ayuda a conocerse, A enamorarse de lo que él mismo es. Y para siempre en la [música vive.

El rey, el músico y el poeta, que son uno mismo en realidad, Narciso y Luis Cernuda, consolidan su mito y escriben su leyenda. El poeta alcanza su deseo: la inmortalidad a través del arte.

Dedicatoria: A los profesores José Antonio Sánchez Marín y María Nieves Muñoz Martín dedico este sentido Homenaje Particular en agradecimiento a tantas experiencias compartidas.

\section{Bibliografía}

CERNUDA, L. Epistolario 1924-1963. Edición a cargo de James Valender. Madrid: Residencia de Estudiantes, 2003.

CERNUDA, L. Las nubes; Desolación de la Quimera. Edición a cargo de Luis Antonio de Villena. Madrid: Cátedra, 2003.

CERNUDA, L. Luis Cernuda: prosa completa. Edición a cargo de Derek Harris y Luis Maristany. Barcelona: Seix Barral, 1975.

CERNUDA, L. Poesía completa. Edición a cargo de Derek Harris y Luis Maristany. Barcelona: Seix Barral, 1977.

CORTINES, J. (Ed.). Actas del Primer Congreso Internacional sobre Luis Cernuda (1902-1963). Sevilla: Universidad de Sevilla, 1990. 
HARRIS, D. La poesía de Luis Cernuda. Granada: Universidad de Granada, 1992.

HILARIO, A. E. D.-P. Las ideas estéticas de Adam Zagajewski y sus fuentes clásicas. 2012. 943 f. Tesis (Doctorado) - Departamento de Filología Griega (Filología Eslava), Facultad de Filosofía y Letras, Universidad de Granada, Granada, 2012.

HUGHeS, B. Luis Cernuda and the Modern English Poets: a Study of the Influence of Browning, Yeats and Eliot on His Poetry. Alicante: Universidad de Alicante, 1987.

LAMILLAR, J. Música cautiva: escritos sobre Luis Cernuda. Sevilla: Renacimiento, 2016.

LÓPEZ RODRÍGUEZ, C. El mito de Grecia en Luis Cernuda. Granada: Universidad de Granada, 1978.

LÓPEZ RODRÍGUEZ, C. Luis Cernuda: la construcción de un mito. In: ACTA UNIVERSITATIS PALACKIANAE OLOMUCENSIS: facultas philosophica. Romanica VII. Vydavatelství Univerzity Palackého, 1998. p. 75-85.

MARTÍNEZ DE CASTILLA, N.; VALENDER, L. 100 años de Luis Cernuda. Actas del Smposio Internacional celebrado en mayo de 2002 en la Residencia de Estudiantes de Madrid y en la Paraninfo de la Universidad de Sevilla. Madrid, Publicaciones de la Residencia de Estudiantes, 2004.

PÍNDARO. Odas y fragmentos: Olímpicas, Píticas, Nemeas, Ístmicas, fragmentos. Introducción, traducción y notas de Alfonso Ortega. Madrid: Gredos, 1995.

PÍNDARO. Píndari carmina cum fragmentis. A cura di A. Turin. Oxford: Oxford University Press, 1952.

PLATO. Symposium. Edited by Kenneth Dover. Cambridge: Cambridge University Press, 1980.

PLATON. El banquete. Traducción de Luis Gil Fernández. Buenos Aires: Aguilar Argentina, 1971.

SCHAERER, M. Luis Cernuda y el reflejo. In: HARRIS, D. (Ed.). Luis Cernuda. El escritor y la crítica. Madrid: Taurus, 1977. 
SILVER, P. Et in Arcadia ego: a Study of the Poetry of Luis Cernuda. London: Tamesis Books, 1965.

TALENS, J. El espacio y las máscaras: introducción a la lectura de Luis Cernuda. Barcelona: Anagrama, 1975.

TERUEL, J. Los años norteamericanos de Luis Cernuda. Valencia: Fundación Gerardo Diego, 2013.

ULACIA, M. El teatro de Narciso: Luis de Baviera escucha Lohengrin. In: CONGRESO SOBRE LUIS CERNUDA (1902-1963), 1., Sevilla, 3-6 maio 1988. Actas... Sevilla: Universidad de Sevilla, 1990. p. 39-49. 